\title{
The Visual Cell Morphology of Pagrus major and Its Adaptive Changes with Shift from Palagic to Benthic Habitats*1
}

\author{
Gunzo Kawamura, ${ }^{* 2}$ Ryohei Tsuda, ${ }^{* 3}$ Hidemi KumaI, ${ }^{* 4}$ \\ and Shinichi OHASHI*2
}

(Accepted April 19, 1984)

\begin{abstract}
The visual cell morphology in 2-90 mm long larvae and juveniles, and adult of the red sea bream Pagrus major was examined histologically. The visual system of the larvae is poorly developed at hatching, but becomes functional in 36 hours. At this time, the eyes are well pigmented, cones are formed, and optic nerves connect with the optic tectum. The visual cells of larvae smaller than $10.6 \mathrm{~mm}$ are all single cones. At $11 \mathrm{~mm} \mathrm{TL}$, the single cones fuse to form twin cones, and rods appear at the same time. Red sea bream shifts from a pelagic to a benthic habitat when about 12-15 mm long. The observed increase in visual sensitivity at $11 \mathrm{~mm}$ appears to be a preadaptation to life at greater depths. Likewise, the specialized retinal region for acute vision shifts from temporal to dorso-temporal at a length of $30 \mathrm{~mm}$, implying a change in visual axis from fore to lower-fore direction, and an adaptation to the change in diet from planktonic to benthic animals.
\end{abstract}

Marine fishes are ideal for the comparative study of the ontogenetic development and functional morphology of the visual system. ALI ${ }^{1)}$ reported that the eyes of the embryo of Oncorhynchus spp. contained only cones and no rods in the retina. Pure-cone retinae have been demonstrated in the earliest stages of many teleosts from different families; the rods appear later, ${ }^{2-8)}$ BOEHLERT ${ }^{9,10)}$ examined the retinal development in postlarval through juvenile Sebastes diploproa, a rockfish which migrates from the surface waters of the California Current to depths of $250-500 \mathrm{~m}$ at the age of approximately one year. He noted the disappearance of single cones, persistence of twin cones, and increase in rod density, all in close temporal association with this change in habitat; the changes mark the shift from high visual acuity in surface prejuveniles to high sensitivity in benthic juveniles.

This paper reports changes in visual cell morphology with growth in red sea bream Pagrus major, a common sparid fish in waters around Japan, which changes from a pelagic to a benthic habit after metamorphosis. Undergoing a considerable change of photic environments, the adults are found predominantly at depths of $150 \mathrm{~m}$ or more. At the larval stage, this species is a typical visual feeder and does not take food at night. ${ }^{12}$

\section{Material and Methods}

Red sea bream larvae and juveniles were obtained from 2 laboratory groups reared at different institutes, specimens at $6.0-17.4 \mathrm{~mm}$ total length (TL) from the Kagoshima Mariculture Center, and specimens as young as newly hatched larvae at $2.0 \mathrm{~mm}$ TL and fish up to $90.4 \mathrm{~mm}$ TL from the Fisheries Laboratory, Kinki University. A 320 $\mathrm{mm}$ long adult was obtained from a local supplier in Kagoshima. Specimens larger than $90.4 \mathrm{~mm}$ were not examined because it is possible that real differences in morphological characteristics and growth exist between wild and reared ones. ${ }^{11}$ )

The retinae of the specimens were examined histologically. The fish were light-adapted, then preserved in Bouin's solution. The small fish (less than $17 \mathrm{~mm}$ ) with intact eyes were embedded in paraffin, and 4-6 $\mu \mathrm{m}$ thick sagittal and transverse sections were made. Serial tangential sections at the bottom of the retina and cross sections of the other retinal parts were also obtained. The

*1 This study was partly supported by a grant from the Ministry of Education, Science and Culture, Japan.

*2 Faculty of Fisheries, Kagoshima University, 4-50-20 Shimoarata, Kagoshima 890, Japan (川村軍藏・大 楅体一：唐思息大学水産学部).

*3 Faculty of Agriculture, Kinki University, 3-4-1 Kowakae, Higashi-Osaka, Osaka 577, Japan (津田良平: 近畿大学费学部).

* Fisheries Laboratory, Kinki University, Uragami, Wakayama 649-51, Japan (熊井英水: 近㖪大学水虐 研究所浦神寨験場). 
eyes from larger individuals were enucleated, and three retinal parts (temporal, dorso-temporal, and bottom) were removed and oriented in paraffin to allow tangential or cross sections. The retina of the adult fish was divided into 33 parts and cross and tangential sections were made. All sections were Azan-stained.

From tangential sections, cone types and their density and arrangement were determined. Cross sections were used to determine rod density. Following BLAXTER and STAINES, ${ }^{4}$ the nature of the visual cells was ascertained by making counts of the distinct ellipsoidal structures (the cone ellipsoids) in the visual cell layer, and of the cell nuclei in the outer nuclear layer in the cross sections.

Total lengths were measured after preservation; the rate of shrinkage is about $15 \%$ for larvae and $1-10 \%$ for juveniles. ${ }^{123}$

\section{Results}

\section{Larvae and Juveniles}

In the newly hatched larvae, the eyes are not pigmented and the lens and retina are poorly differentiated (Plate I. A). The lens cells are arranged spherically and the cells in the inner retinal layer are arranged radially. At 10 hours from hatching, the lens cells show the first signs of for-

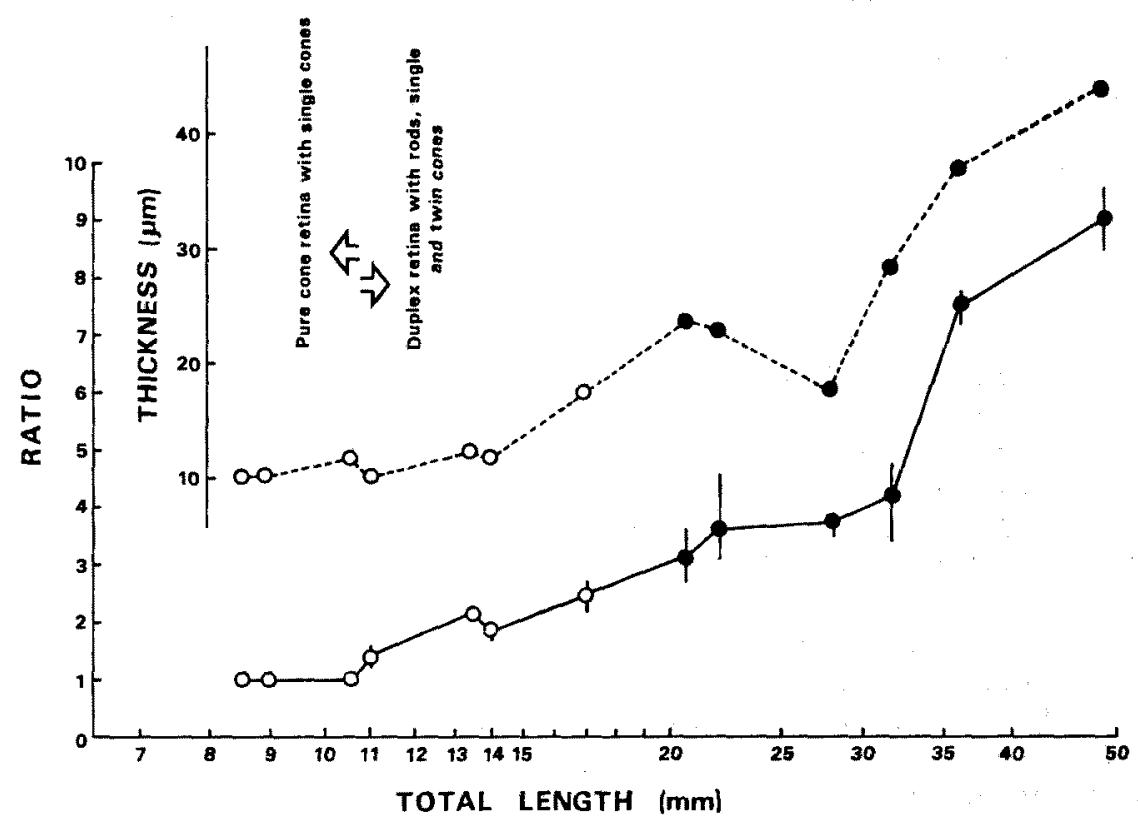

Fig. 1. Change in the nuclei-cone ratio and in thickness of outer nuclear layer in the retinae of red sea bream. The ratio exceeded 1.0 when the fish were $11 \mathrm{~mm}$ long and the rods appeared, and subsequently increased with growth. The thickness also increased with growth showing an increase in rod density. Closed circle, reared at the Fisheries Laboratory, Kinki University; open circle, reared at the Kagoshima Mariculture Center. Vertical bars through circles show the range of ratio calculated. Total length of the fish is shown in log scale.

Plate 1

Photomicrographs showing the development of the eye of red sea bream. Abbreviations: $\mathrm{CO}$, cone; G, ganglion layer; IC, inner nuclear layer; IP, inner plexiform layer; L, lens; ON, outer nuclear layer; PE, pigment epithelium; R, retina; NM, free neuromast. Scale, $30 \mu \mathrm{m}$.
A. Newly hatched larva.
B. Larva at 26 hours from hatching.
C. Larva at 36 hours from hatching.
D. Larva at 36 hours from hatching. Optic nerve fibers leaving the eye and decussating with fibers from the other eye can be seen (arrows).
E. Tangential section showing a regular arrangement of single cones of $7 \mathrm{~mm}$ TL fish.
F. Tangential section showing a regular quadrilateral cone pattern of $17 \mathrm{~mm}$ TL fish. 


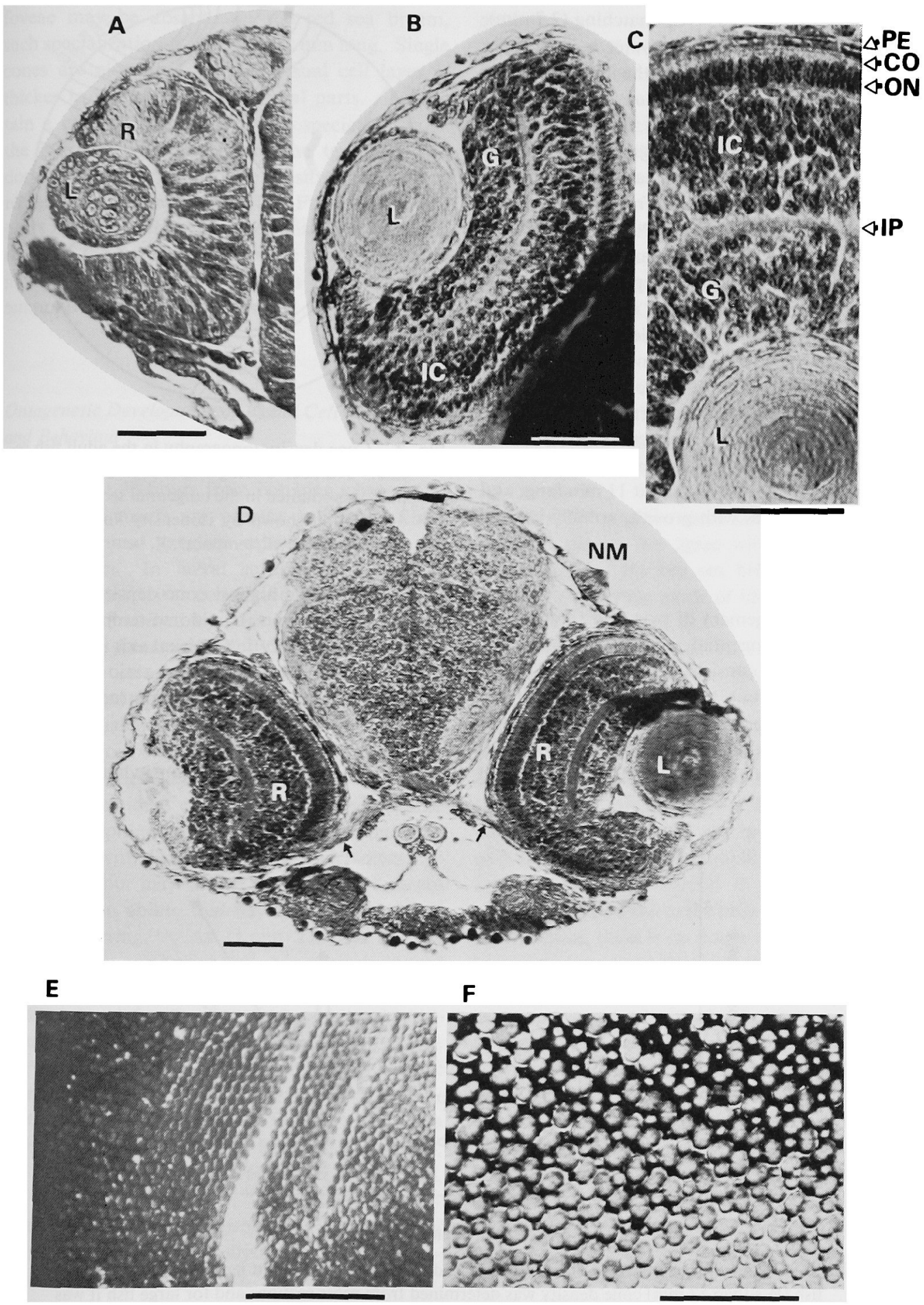


mation of two layers, and the retinal cells increase in number. At 26 hours from hatching $(2.7 \mathrm{~mm})$, pale pigmentation is seen, the outer nuclear layer (visual cell nuclei) is developed, the inner and outer plexiform layers are formed, but no optic nerve fibers can yet be seen (Plate I, B). At 36 hours from hatching, the eye is well pigmented, cones are formed, and optic nerve fibers can be seen leaving the eye, decussating with fibers from the other eye, and leading into the tectum (Plate I, C and D). At 60 hours from hatching $(3.1 \mathrm{~mm}$ ) cones increase in number, and the pigment epithelium layer is thick. The larvae start feeding on the third day.

The visual cells in larvae smaller than $11 \mathrm{~mm} \mathrm{TL}$ are all single cones; there are neither twin cones nor rods (Plate I, E). Twin cones were found at 11, 13.5, and $14 \mathrm{~mm}$ long, arranged irregularly and not in any mosaic. A regular quadrilateral cone pattern is found in fish larger than $17 \mathrm{~mm}$ (Plate I, F). Rods first appear at $11 \mathrm{~mm}$ long, and the density increases with growth, notably beyond $35 \mathrm{~mm}$ (Fig. 1).

\section{Adult}

A regular arrangement of twin and single cones can be seen in tangential sections of the retina. The cone pattern consists of quadrilateral units, each formed by four twin cones surrounding a central single cone. The ratio of single to twin cones is $1: 2$ over the entire retina. Cone density varies by region of the retina. As already noted

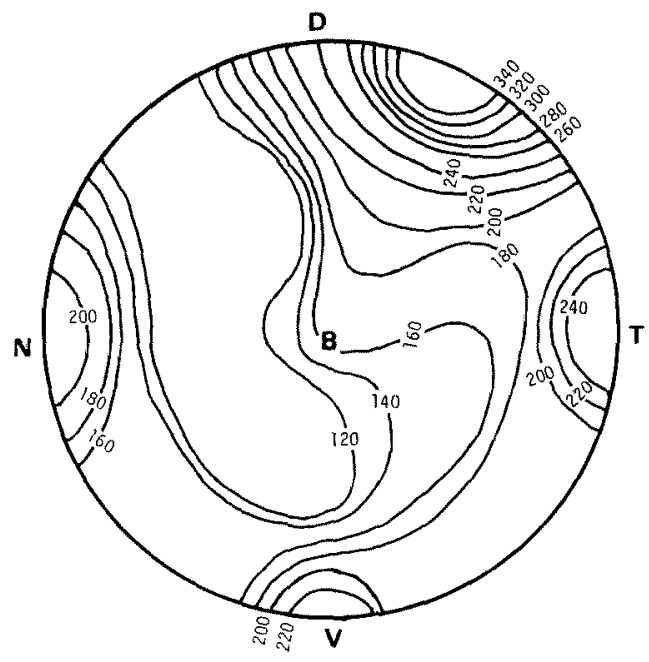

Fig. 2. Cone density topography in the adult fish retina. Number of single and twin cones in 0.01 $\mathrm{mm}^{2}$ was counted in the tangential sections and its distribution shown by isodensity lines. $\mathrm{B}$, bottom; D, dorsal; T, temporal; V, ventral; N, nasal.

by TAMURA, ${ }^{133}$ the highest cone density in red sea bream is in the dorsal to dorso-temporal retinal region (Fig. 2), indicating a visual axis in the lowerfore direction. The nuclei-cone ratio varies from 15 to 28 by region, highest at the bottom.

\section{Specialization in Cone Density}

Most fishes have an area somewhat specialized

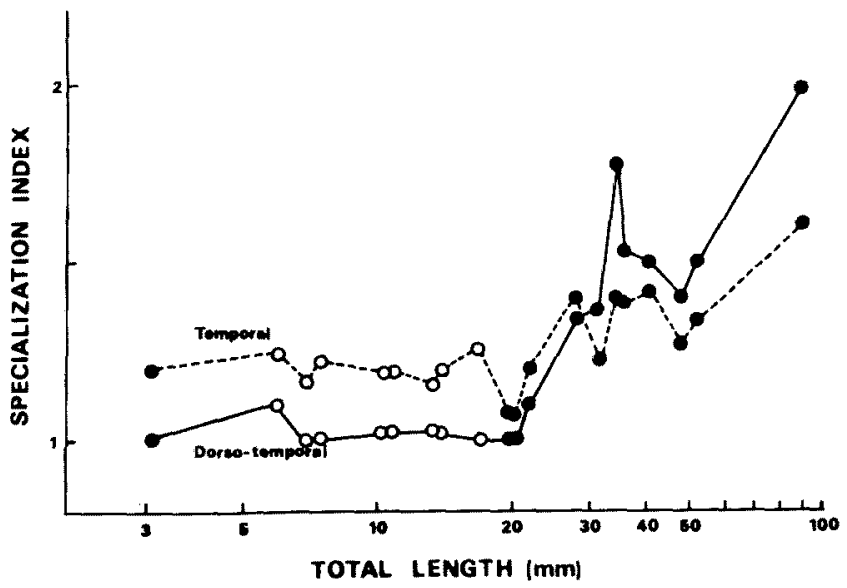

Fig. 3. Degree of specialization of the retina of red sea bream at different lengths. For the small fish (less than $17 \mathrm{~mm}$ ) cone density was determined from cross sections and for large fish it was determined from tangential sections. Note that the lines cross between $28 \mathrm{~mm}$ TL and $32 \mathrm{~mm}$ TL showing the most specialized region shifted from temporal to dorso-temporal regions. Open and closed circles, same as in Fig. 1. 
for more acute vision, even though true areae or foveae may be absent. In the red sea bream, such specialization is found at $3.1 \mathrm{~mm}$ long. Single cones are elongated and the visual cell layer is thicker in the temporal and nasal parts. To obtain a comparable index of this specialization, ${ }^{13)}$ the ratio of cone density in the temporal and dorso-temporal regions to the density in the bottom region was calculated (Fig. 3). From this, it appears that the most highly specialized region in the retina of the red sea bream is the temporal region in the young larvae, but shifts to the dorsotemporal region at $30 \mathrm{~mm}$ long.

\section{Discussion}

\section{Ontogenetic Development of Visual Cell Morphology and Behaviour}

The eyes of the red sea bream can be considered functional at 36 hours from hatching when visual cells and pigments are present and nerve fibers from the retinal ganglion cells connect with the optic tectum. In larval sardine and anchovy, the visual system was considered functional as the optic nerves reached the tectum ${ }^{14}$; in the larval Oplegnathus fasciatus, ${ }^{7}$ Takifugu rubripes, ${ }^{*}$ and Paralichthys olivaceus, ${ }^{*}$ phototaxis and feeding were observed when the eyes became pigmented and the visual nerve fibers from the retina made the connection with the tectum. Red sea bream at the yolk-sac stage ( 24 hours from hatching) with non-functional visual system, exhibits regular movement up and down a water column that correlates well with diel changes in solar irradiance. ${ }^{15}$ ) Such behaviour may be due to extraretinal photosensitivity, an ability that has been demonstrated in blind herring. ${ }^{18)}$ At $11 \mathrm{~mm} \mathrm{TL}$, the red sea bream retina underwent a big morphological change: single cones fused to form twin cones and rods appeared for the first time, presumably increasing sensitivity to lower light levels. YaNO and OGAWA ${ }^{17)}$ observed changes in the vertical distribution of red sea bream larvae with changes in light intensity, and found that the light intensities at the depths prefered by the larvae at $5-7,13-15$, and $19-21 \mathrm{~mm}$ long were $1600-2200$, below 200 , and $70-100 \mathrm{~lx}$ respectively. This change in preferred light intensity with growth can be attributed to the change in visual sensitivity, and can be related to the change in habitats.
Change in Habitat and Adaptive Change in Morphology

The larvae of red sea bream are known to have a vertical distribution ranging from surface to $50 \mathrm{~m}$ deep, with greater numbers at relatively deep layers. ${ }^{18)}$ While the small larvae less than $8 \mathrm{~mm}$ long are commonly collected with the larva net, larger larvae are usually very few, although HaSEGAWA et al. ${ }^{18)}$ reported high catch of 10-15 $\mathrm{mm}$ red sea bream with the larva net off Noto Peninsula in the Japan Sea. TANAKA ${ }^{202}$ noted that the red sea bream larvae collected with the larva net from the East China Sea and the coastal waters of Kyushu had maximum lengths of $14-15 \mathrm{~mm}$ $T L$, regardless of collection ground, season, and towing method. On the other hand, the common minimum size of the red sea bream collected with various bottom-operated fishing gear, ${ }^{21-27)}$ or from the stomach contents of benthic predators ${ }^{27)}$ is $10-15 \mathrm{~mm}$ TL. Considering the avoidance of samplers, ${ }^{20,28)}$ and the mesh selectivity of bottomoperated gear, ${ }^{21)}$ we agree with TANAKA ${ }^{20)}$ who concluded that the red sea bream shifts from a pelagic to a benthic mode of life when they attain a length of $12-15 \mathrm{~mm}$ TL.

The red sea bream at $12-15 \mathrm{~mm}$ has already undergone metamorphosis. Segmentation of soft rays is almost completed and fin branching is observed, ${ }^{30,31)}$ scale formation begins, ${ }^{32)}$ the blackstriped pigmentation is in progress, ${ }^{83)}$ swimming speed and distance markedly increase, ${ }^{84-30)}$ and larger food is preferred. ${ }^{37)}$ The rate of organ development of the red sea bream larvae varies with temperature and the quality of food given, ${ }^{11}$ and one has to be careful in relating the morphology of reared fish to the behaviour of wild ones. Nevertheless, there is no doubt that many changes in morphology and behaviour of this species occur in temporal association with its migration from the surface waters to the benthic habitat.

The increase in visual sensitivity at $11 \mathrm{~mm} \mathrm{TL}$ is an adaptation to the prevailing lower levels of irradiance in the deeper waters. The shift in visual axis from fore to lower-fore direction at around $30 \mathrm{~mm}$ TL is an adaptation to the change in diet and feeding habit. According to OMORI, ${ }^{22}$ the stomach contents of the red sea bream juveniles caught with bottom operated gear in Yuya Bay facing the East China Sea show typical diurnal feeding with peaks in the morning and late afternoon. Diet consists predominantly of zooplank-

* K. Ishida and G. Kawamura, paper presented at the Annual Meeting of the Japanese Society of Scientific Fisheries on April 2, 1983 (Tokyo) and on October 10, 1983 (Kyoto). 
ton such as copepods (mostly Acartia clausi which swarm at the bottom ${ }^{88-40)}$ ) and appendicularians in fish at $20-30 \mathrm{~mm}$ long, but changes to caprellidean amphipods in fish at $30 \mathrm{~mm}$ long, and to tubicolous gammaridean amphipods in fish at $70 \mathrm{~mm}$ long. ${ }^{22}$ A similar change in stomach contents is also seen in juveniles from Shijiki Bay. ${ }^{38)}$ All the observed changes in visual morphology and behaviour together with other features in larval development in the red sea bream occur prior to, and presumably in anticipation of, the change in habitat and habits.

The authors thank Mr. M. NAKamura of the Fisheries Laboratory, Kinki University and Mr. S. Fuлta of the Kagoshima Mariculture Center for their kind arrangement of samples.

\section{References}

1) M. A. Ali; Can. J. Zool., 37, 965-996 (1959).

2) J. H.S. BLAXTER: J. Exp. Biol., 48, 39-53 (1968).

3) J. H. S. Blaxter: J. Exp. Biol., 51, 221-230 (1969).

4) J. H. S. Blaxter and M. Staines: J. Mar. Biol. Ass. U. K., 50, 449-460 (1970).

5) J. H. S. BLAXTER: in "Vision in Fishes" (ed. by M. A. ALI), Plenum Press, N. Y., 1975, pp. 427443.

6) G. Kawamura, Y. MUKay, and H. Ohta: Bull. Japan. Soc. Sci. Fish., 49, 1527-1532 (1983).

7) G. Kawamura, S. Kadowaki, and Y. Mukat: Min. Rev. Data File Fish. Res. Kagoshima Univ., 3, 45-48 (1984).

8) G. Kawamura and Y. Mukat: Min. Rev. Data File Fish. Res. Kagoshima Univ., 3, 49-54 (1984).

9) G. W. BOEHLERT: Science, 202, 309-311 (1978).

10) G.W. Boehlert: Rev. Can. Biol., 38, 265-280 (1979).

11) C. KrTamma: Spec. Rep. Nagasaki Pref. Inst. Fish., 5, 1-92 (1978).

12) O. FukuHaRa: The Aquaculture, 27, 129-136 (1979).

13) T. Tamura: Bull. Japan. Soc. Sci. Fish., 22, 536-557 (1957).

14) H. SchWaSSMANN: CalCOFL Rep., 10, 64-70 (1963).

15) R. Tsuda and W. Sakamoto: Bull. Japan. Soc. Sci. Fish., 49, 829-837 (1983).

16) W. Wales: in "Vision in Fishes" (ed. by M. A. ALI), Plenum Press, N. Y., 1975, pp. 445-450.

17) I. YANo and Y. OgaWA: Bull. Natl. Res. Inst. Aquaculture, 3, 45-49 (1982).
18) M. Tanaka, M. SugiYama, K. Tamal, and K. MIYAJI: Bull. Seikai Reg. Fish. Res. Lab., 59, 33-45 (1983).

19) S. HaSEgawa, K. Ito, and F. Kato: Bull. Jap. Sea Reg. Fish. Res. Lab., 33, 31-40 (1982).

20) M. Tanaka: Bull. Seikai Reg. Res. Lab, 54, 231-258 (1980).

21) K. MORI: Bull. Seikai Reg. Fish. Res. Lab., 54, 59-78 (1980).

22) M. OMORI: Bull. Seikai Reg. Fish. Res. Lab., 54, 93-109 (1980).

23) M. Azeta, R. Ikemoto, and M. Azuma: Bull. Selkai Reg. Fish. Res. Lab., 54, 259-278 (1980).

24) M. Azuma, M. Azeta, and K. Mitsumaru: Bull. Seikai Reg. Fish. Res. Lab., 59, 101-118 (1983).

25) Anonymous: 57 th Kaiyusei Gyorui Kyodo Horyu Jikken Hokokusho, Japan Sea Regional Fisheries Research Laboratory and Nihon Saibai Gyogyo Kyokai, 1983, pp. 185.

26) Anonymous: 56 th Kaiyusei Gyorui Kyodo Horyu Jikken Hokokusho, Japan Sea Regional Fisheries Research Laboratory and Nihon Saibai Gyogyo Kyokai, 1982, pp. 41-42.

27) Anonymous: 54th Kaiyusei Gyorui Kyodo Horyu Jikken Hokokusho, Japan Sea Regional Fisheries Research Laboratory and Nihon Saibai Gyogyo Kyokai, 1980, pp. 85-89.

28) R. I. Clutter and M. ANraku: in "Zooplankton Sampling" Part 1 (ed. by D. I. Tranter), UNESCO Monogr. Oceanogr. Meth. 2, 1968, pp. 57-76.

29) M. TaNaka: Suisan Doboku, 16, 47-57 (1979).

30) O. Fukuhara: Bull. Nansei Reg. Fish. Res, Lab., 9, 1-11 (1976).

31) O. Fukuhara: Bull. Nansei Reg. Fish Res, Lab., 11, 19-25 (1978).

32) O. Fukuhara: Bull. Nansei Reg. Fish. Res, Lab., 9, 13-18 (1976).

33) O. FukUHARA: Bull. Nansei Reg. Fish. Res. Lab., 11, 1-18 (1978).

34) O. FukUHARA and T. KISHTDA: Bull. Nansei Reg. Fish. Res. Lab., 12, 9-20 (1980).

35) T. Kishida and O. FukuHara: Bull. Nansei Reg. Fish. Res. Lab., 13, 9-17 (1981).

36). I. Yano and Y. Ogawa: Bull. Natl. Res. Inst. Aquaculture, 2, 49-54 (1981).

37) R. Okamoto, H. Matsunaga, K. Funae, and M. Hisaoka: Bull. Nansei Reg. Fish .Res. Lab., 14, 19-31 (1982).

38) K. KIso: Bull. Seikai Reg. Fish. Res. Lab., 54, 291-306 (1980).

39) M, ANRAKU: Mar. Biol., 30, 79-87 (1975).

40) T. Urda: Bull. Seikai Reg. Fish. Res. Lab., 54, 171-194 (1980). 